Gut, 1978, 19, 249-252

\title{
Significance of anergy to dinitrochlorobenzene (DNCB) in inflammatory bowel disease: family and postoperative studies ${ }^{1}$
}

\author{
S. MEYERS ${ }^{2}$, D. B. SACHAR, R. N. TAUB, AND H. D. JANOWITZ
}

From the Division of Gastroenterology and Hematology of the Department of Medicine, The Mount Sinai Hospital and the Mount Sinai School of Medicine of the City University of New York, New York, USA

SUMMARY To evaluate the pathogenetic significance of impaired cellular immunity in inflammatory bowel disease (IBD), we have measured the cutaneous responsiveness to dinitrochlorobenzene (DNCB) among 58 patients with IBD, 33 with Crohn's disease and 25 with ulcerative colitis, 63 of their clinically normal relatives, 24 additional ileitis and colitis patients who had undergone resection of all visibly diseased bowel, and 23 control subjects. Cutaneous anergy to DNCB was demonstrated among $70 \%$ of the patients with CD and $48 \%$ of those with UC, as against only $9 \%$ of controls $(P<0.001)$. There was no increased incidence of anergy among either 44 first-degree relatives $(7 \%)$ or 19 spouses $(0 \%)$, nor was there any special proclivity toward anergy among six pairs of patients with familial inflammatory bowel disease. In Crohn's disease, anergy was still present after bowel resection in six of 10 patients $(60 \%)$, while in ulcerative colitis anergy was found after colectomy in only two of 14 patients (14\%). Our data suggest that the immune defect in patients with inflammatory bowel disease may be a secondary phenomenon. In ulcerative colitis, the defect appears to reverse after colectomy, but in Crohn's disease it persists despite resection. This finding is consistent with the observed tendency of Crohn's disease, but not ulcerative colitis, to inexorable postoperative recurrence.

Patients with inflammatory bowel disease have been reported to manifest various defects in their cellular immune system (Jones et al., 1969; Strickland et al., 1974; Meuwissen et al., 1975). Although there has been controversy over this subject (Sachar et al., 1977; Strickland and Sachar, 1977) our studies have consistently noted impaired lymphocyte responsiveness in vitro, depressed T-lymphocyte counts, and cutaneous anergy to dinitrochlorobenzene (DNCB) among many patients with Crohn's disease and with ulcerative colitis (Sachar et al., 1973; Sachar et al.,

\footnotetext{
${ }^{1}$ This paper was presented in part at the American Federation of Clinical Research Meetings, Eastern Section, 14 January 1977, Boston, Mass., and published in abstract form in Clinical Research, 24, 628A, 1976. The study was supported by a grant from the National Foundation for Ileitis and Colitis, Inc., and by Grant No. I-RO1-AM19695-01 GMA of the National Institutes of Health.

2Address for reprint requests: Dr Samuel Meyers, Division of Gastroenterology, Annenberg 23-02, Mount Sinai School of Medicine, New York, New York 10029, USA.
}

Received for publication 19 October 1977
1976; Meyers et al., 1976).

The pathogenetic significance of these findings remains uncertain. It appears that these immunological defects are not simple secondary manifestations of disease severity, as they do not correlate with activity, duration, or anatomical extent of disease. We still do not know, however, if these defects are secondary to an as yet unrecognised facet of disease or if they represent some pre-existing, perhaps genetic, abnormality. In an attempt to clarify this issue, we have performed DNCB tests on 58 patients with Crohn's disease and ulcerative colitis, on 63 of their clinically normal relatives, and on an additional 24 patients with ileitis and colitis.

\section{Methods}

\section{PATIENTS}

We performed DNCB skin tests on 33 patients with Crohn's disease and 25 with ulcerative colitis, about half of whom have been included in a previous report (Meyers et al., 1976). The Crohn's disease 
group included five with only colonic disease, which was differentiated from ulcerative colitis by sparing of the rectum and by histological demonstration of granulomas in endoscopic biopsies or surgical specimens. The remaining 28 patients had obvious small intestinal disease, either ileitis or ileocolitis. The 25 ulcerative colitis patients had typical protocolitis with no clinical or radiological features of Crohn's disease. Many of the patients were taking sulphasalazine at the time of the study, but none had received ACTH, corticosteroids, or other immunosuppressive therapy, or had undergone any surgery, within the preceding month. All of the patients were ambulatory and not hospitalised, and none was considered clinically malnourished, hypoalbuminaemic, or lymphopenic.

We also tested 63 relatives of 25 ileitis and colitis patients. Thirty-one subjects were related to 13 propositi with Crohn's disease, six of whom were themselves anergic to dinitrochlorobenzene. These 31 relatives included four parents, nine children, seven siblings, and 11 spouses. The other 32 relatives were provided by 12 ulcerative colitis propositi, four of whom were anergic, and they comprised 10 parents, seven children, seven siblings, and eight spouses. The relatives had no histories of bowel disease and were in apparently good health at the time of study.

The 24 postoperative subjects were studied two months to 25 years after resection of their inflammatory bowel disease. All were free of gastrointestinal symptoms at the time of study and had had radiological confirmation of the absence of detectable inflammatory bowel disease within the preceding six months. Patients studied earlier than six months after operation had grossly normal remaining bowel and histologically normal margins of resected tissue. Ten patients had had Crohn's disease and 14 ulcerative colitis. Nine of the 10 Crohn's disease subjects had undergone segmental resection with internal anastomosis, while one with granulomatous colitis had undergone total proctocolectomy and ileostomy. All 14 ulcerative colitis subjects had also had total proctocolectomy and ileostomy.

Twelve healthy normal control subjects and 11 subjects with various other digestive disorders constituted the control groups. These other digestive disorders included lactase deficiency (one), irritable bowel syndrome (two), coeliac sprue (one), acute salmonella enteritis (three), active schistosomal colitis (one), and peptic ulcer (three). Patient and control groups were of similar age and sex composition.

Before study, the research nature and possible adverse effects of the dinitrochlorobenzene test were fully discussed with the subjects, all of whom gave their informed consent.
DINITROCHLOROBENZENE (DNCB) TESTING The method for DNCB testing was described by Catalona et al. (1972). A sensitising dose of $2000 \mu \mathrm{g}$ DNCB in $0.1 \mathrm{ml}$ acetone was applied evenly over a circular area of $2 \mathrm{~cm}$ in diameter on the volar surface of the forearm. The solvent was allowed to evaporate and the area was covered with a dry dressing for 24 hours. If no primary response occurred, a challenge dose of $100 \mu \mathrm{g}$ DNCB was applied 12 to 14 days later. All tests were performed by the same physician. A positive response consisted of induration and erythema at the test site 10 to 12 days after primary sensitisation or two to three days after secondary challenge. Even if skin irritation and itching occurred, the response was not considered positive unless induration was noted. In order to avoid problems of bias and of possible false negative readings, any equivocal reaction was automatically recorded as positive.

\section{STATISTICAL METHODS}

Analysis of significance was carried out using the chisquare test.

\section{Results}

The results of DNCB tests in the 58 ileitis and colitis patients are shown in Table 1 . All subjects demonstrated a primary irritant response, manifested by erythema and frequently by itching and vesiculation.

Table 1 Anergy to DNCB in Crohn's disease and ulcerative colitis

\begin{tabular}{llll}
\hline Diagnosis & \multicolumn{2}{l}{ Patients } \\
\cline { 2 - 4 } & No. & \multicolumn{2}{l}{ Anergic } \\
\cline { 2 - 4 } & & $($ no. $)$ & $(\%)$ \\
\hline Crohn's disease & 33 & 23 & $70^{*}$ \\
Ulcerative colitis & 25 & 12 & $48^{*}$ \\
Normal controls & 12 & 1 & $8 \cdot 5$ \\
Digestive disease controls & 11 & 1 & 9 \\
\hline
\end{tabular}

Significant difference from controls: ${ }^{*} \mathrm{P}<0.001$.

Delayed hypersensitivity was not considered to be present unless induration occurred. Anergy was demonstrated in $70 \%$ of the Crohn's disease patients and $48 \%$ of those with ulcerative colitis. Although anergy tended to be more common in Crohn's disease than in ulcerative colitis, this difference does not achieve statistical significance. On the other hand, the prevalence of anergy in both Crohn's disease and ulcerative colitis patients was very much greater than the $8.5 \%$ frequency in 12 normal control subjects and the $9 \%$ frequency in 11 control patients with other digestive disorders $(P<0.001)$. 
The responses of the patients' relatives are listed in Tables 2 and 3. None of the relatives of those with Crohn's disease demonstrated anergy (Table 2). Among the relatives of the ulcerative colitis patients (Table 3), only three were anergic, two of them related to normally reactive propositi and one to an anergic propositus. The incidence of anergy among first-degree relatives and spouses was therefore no higher than in control groups.

Table 2 Anergy to DNCB among relatives of 13 patients with Crohn's disease

\begin{tabular}{lll}
\hline Relation & \multicolumn{2}{l}{ Relatives } \\
\cline { 2 - 3 } & No. & No. with anergy \\
\hline Parents & 4 & 0 \\
Children & 9 & 0 \\
Siblings & 7 & 0 \\
Spouses & 11 & 0 \\
Total & 31 & 0 \\
\hline
\end{tabular}

Table 3 Anergy to DNCB among relatives of 12 patients with ulcerative colitis

\begin{tabular}{lll}
\hline Relation & \multicolumn{2}{l}{ Relatives } \\
\cline { 2 - 3 } & No. & No. with anergy \\
\hline Parents & 10 & 2 \\
Children & 7 & 0 \\
Siblings & 7 & 1 \\
Spouses & 8 & 0 \\
Total & 32 & 3 \\
\hline
\end{tabular}

There were six familial cases among our patients with inflammatory bowel disease - that is, five pairs of first degree relatives and one husband-wife pair both of whom had ileitis or colitis. Table 4 analyses the DNCB results in this specific subgroup of patients. Cutaneous reactivity was either completely normal or else discordant in five of the pairs, with only one father-daughter pair concordant for anergy. Thus, anergy to DNCB appears not to have any special predilection for familial cases of inflammatory bowel disease.

Results of the postoperative studies are listed in Table 5. In Crohn's disease, anergy was present in just about the same frequency with disease in situ $(70 \%)$ and post-resection (60\%). The situation was quite different in ulcerative colitis, however. While $48 \%$ of unoperated ulcerative colitis patients were anergic, anergy was present in only $14 \%$ of the postcolectomy group, a statistically significant difference $(P<0.05)$. Indeed, the $14 \%$ frequency of anergy postcolectomy in ulcerative colitis patients is not statistically significantly different from the frequency in control subjects.
Table 4 DNCB responses in familial inflammatory bowel disease

\begin{tabular}{lll}
\hline Responses & $\begin{array}{l}\text { Familial } \\
\text { relationships }\end{array}$ & Disease \\
\hline Normal & $\begin{array}{l}\text { Brother } \\
\text { Brother } \\
\text { Mother } \\
\text { Son }\end{array}$ & Ulcerative colitis \\
$\begin{array}{l}\text { Father } \\
\text { Son } \\
\text { Father } \\
\text { Daughter } \\
\text { Mother } \\
\text { Daughter }\end{array}$ & Ulcerative colitis \\
Discordant & $\begin{array}{l}\text { Husband } \\
\text { Wife }\end{array}$ & Crohn's disease \\
\hline
\end{tabular}

Table 5 Anergy to $D N C B$ with and without resection of disease

\begin{tabular}{|c|c|c|c|}
\hline \multirow[t]{3}{*}{ Disease } & \multicolumn{3}{|c|}{ Putients } \\
\hline & \multirow[t]{2}{*}{ No. } & \multicolumn{2}{|c|}{ Anergic } \\
\hline & & (no.) & $(\%)$ \\
\hline \multicolumn{4}{|l|}{ Crohn's disease } \\
\hline No resection & 33 & 23 & $70^{*}$ \\
\hline Resection & 10 & 6 & $60^{*}$ \\
\hline \multicolumn{4}{|l|}{ Ulcerative colitis } \\
\hline No resection & 25 & 12 & $48 *$ \\
\hline Resection & 14 & 2 & 14 \\
\hline
\end{tabular}

Significant difference from controls: ${ }^{*} \mathrm{P}<0.001$.

\section{Discussion}

While this study further supports our contention that cellular immunity is impaired in most patients with inflammatory bowel disease, it does not identify the defective step in the pathway of cutaneous contact sensitivity. The DNCB test involves both induction de novo of contact sensitivity and the elicitation of a cutaneous contact sensitivity reaction. As all patients mounted a primary irritant response, it is not likely that the anergy to DNCB was attributable to the defective acute inflammatory response demonstrated in Crohn's disease (Segal and Loewi, 1976). Reports of normal conventional skin responses in ulcerative colitis (Binder et al., 1966; Bolton et al., 1974) suggest that the defect might be in primary sensitisation to new antigens. Impaired conventional skin responses in Crohn's disease (Meuwissen et al., 1975) may point to a more extensive defect, including the recall of sensitivities acquired before the onset of disease.

In any event, our family studies indicate that, while cutaneous anergy to DNCB is present in most patients with inflammatory bowel disease, it does not occur with increased frequency among their relatives or with any special predilection for familial cases of 
ileitis and colitis. These results suggest that, while inflammatory bowel disease does have a distinct familial tendency and also manifests interactions of genetic and immune factors (Kirsner, 1973; Lewkonia and McConnell, 1976), the cellular immune deficiency observed in ileitis and colitis patients has no demonstrable primary role in producing genetic predisposition to these diseases.

An increased prevalence of lymphocytotoxic antibody has been noted in patients with inflammatory bowel disease and their household contacts (Korsmeyer et al., 1975), and this has been taken as possible evidence for the presence of a common environmental agent. In contrast, the normal DNCB reactivity among every one of the 19 spouses in our report, and even in one member of the husband-wife pair with inflammatory bowel disease, indicates that, whatever factor may elicit the lymphocytotoxic antibody, it is not operative in the induction of the cellular immune deficiency.

Our postoperative studies indicate that removal of the target organ may reverse the cutaneous anergy in ulcerative colitis. This observation, coupled with the failure to demonstrate any increased frequency of anergy among patients' relatives, suggests that the immune defect may be a secondary phenomenon. On the other hand, surgical resection of all visibly diseased tissue in Crohn's disease has no apparent influence on the immune deficiency. Of course, it would have been ideal to study the same individuals both pre and postoperatively, but this was not feasible because the patients who required resection were generally receiving ACTH, corticosteroid, or other immunosuppressive therapy. In the one patient with Crohn's colitis who was serially studied before and after surgery, however, anergy was, in fact, demonstrated on both occasions. In any event, our observations in Crohn's disease suggest that the anergy-inducing factor in these patients persists despite bowel resection. This concept is consistent with recent observations that Crohn's disease seems to produce subtle microscopic and physiological abnormalities throughout the entire gut (Goodman et al., 1976; Dunne et al., 1977) and it may be reflected in the known tendency of Crohn's disease to recur inexorably after operation (Greenstein et al., 1975).

The authors are grateful to Diane Gaffield for invaluable help both in contacting patients and in the preparation of the manuscript.

References

Binder, H. J., Spiro, H. M., and Thayer, W. R., Jr. (1966).
Delayed hypersensitivity in regional enteritis and ulcerative colitis. American Journal of Digestive Diseases, 11, 572-574.

Bolton, P. M., James, S. L., Newcombe, R. G., Whitehead, R. H., and Hughes, L. E. (1974). The immune competence of patients with inflammatory bowel disease. Gut, 15, 213219.

Catalona, W. J., Taylor, P. T., Rabson, A. S., and Chretien, P. B. (1972). A method for dinitrochlorobenzene contact sensitization. New England Journal of Medicine, 286, 399. 402.

Dunne, W. T., Cooke, W. T., and Allan, R. N. (1977). Enzymatic and morphometric evidence for Crohn's disease as a diffuse lesion of the gastrointestinal tract. Gut, 18, 290294.

Goodman, M. J., Skinner, J. M., and Truelove, S. C. (1976). Abnormalities in the apparently normal bowel mucosa in Crohn's disease. Lancet, 1, 275-278.

Greenstein, A. J., Sachar, D. B., Pasternack, B. S., and Janowitz, H. D. (1975). Reoperation and recurrence in Crohn's colitis and ileocolitis: crude and cumulative rates. New England Journal of Medicine, 293, 685-690.

Jones, J. V., Housley, J., Ashurst, P. M., and Hawkins, C. F. (1969). Development of delayed hypersensitivity to dinitrochlorobenzene in patients with Crohn's disease. Gut, 10, 52-56.

Kirsner, J. B. (1973). Genetic aspects of inflammatory bowel disease. Clinics in Gastroenterology, 2, 557-575.

Korsmeyer, S. J., Williams, R. C., Jr., Wilson, I. D., and Strickland, R. G. (1975). Lymphocytotoxic antibody in inflammatory bowel disease. A family study. New England Journal of Medicine, 293, 1117-1120.

Lewkonia, R. M., and McConnell, R. B. (1976). Familial inflammatory bowel disease-heredity or environment? Gut, 17, 235-243.

Meuwissen, S. G. M., Schellekens, P. T. A., Huismans, L., and Tytgat, G. N. (1975). Impaired anamnestic cellular immune response in patients with Crohn's disease. Gut, 16, 854-860.

Meyers, S., Sachar, D. B., Taub, R. N., and Janowitz, H. D. (1976). Anergy to dinitrochlorobenzene and depression of T-lymphocytes in Crohn's disease and ulcerative colitis. Gut, 17, 911-915.

Sachar, D. B., Meyers, S., and Janowitz, H. D. (1977). Anergy in Crohn's disease (Letter). British Medical Journal, 1, 712-713.

Sachar, D. B., Taub, R. N., Brown, S. M., Present, D. H., Korelitz, B. I., and Janowitz, H. D. (1973). Impaired lymphocyte responsiveness in inflammatory bowel disease. Gastroenterology, 64, 203-209.

Sachar, D. B., Taub, R. N., Ramachandar, K., Meyers, S., Forman, S. P., Douglas, S. D., and Janowitz, H. D. (1976). T- and B-lymphocytes and cutaneous anergy in inflammatory bowel disease. Annals of the New York Academy of Sciences, 278, 565-572.

Segal, A. W., and Loewi, G. (1976). Neutrophil dysfunction in Crohn's disease. Lancet, 2, 219-221.

Strickland, R. G., Korsmeyer, S., Soltis, R. D., Wilson, I. D., and Williams, R. C., Jr. (1974). Peripheral blood T and B cells in chronic inflammatory bowel disease. Gastroenterology, 67, 569-577.

Strickland, R. G., and Sachar, D. B. (1977). The immunology of inflammatory bowel disease. In Progress in Gastroenterology, vol. III, pp. 821-838. Edited by G. B. J. Glass. Grune and Stratton: New York. 